\title{
Conversion Timing of Following-Up Thermal Recovery Approaches of Post-CHOP for Foamy Extraheavy Oil Reservoirs
}

\author{
Zhaopeng Yang $\mathbb{D},{ }^{1}$ Xingmin $\mathrm{Li}^{1}{ }^{1}$ Yang Yu $\mathbb{D}^{1},{ }^{1} \mathrm{Jia}_{\mathrm{Xie}}{ }^{2}$ and Yintao Dong ${ }^{3}$ \\ ${ }^{1}$ PetroChina Research Institute of Petroleum Exploration and Development, Beijing 100083, China \\ ${ }^{2}$ PetroChina Liaohe Oilfield Company, Panjin, 124010 Liaoning, China \\ ${ }^{3}$ CNOOC Research Institute, Beijing 100028, China
}

Correspondence should be addressed to Zhaopeng Yang; yangzhaopeng@petrochina.com.cn

Received 8 September 2021; Revised 22 November 2021; Accepted 23 November 2021; Published 14 December 2021

Academic Editor: Afshin Davarpanah

Copyright (C) 2021 Zhaopeng Yang et al. This is an open access article distributed under the Creative Commons Attribution License, which permits unrestricted use, distribution, and reproduction in any medium, provided the original work is properly cited.

\begin{abstract}
The purpose of this study is to determine the optimal conversion timing of follow-up thermal recovery approaches of post-CHOP for foamy extraheavy oil reservoirs. The microscopic visualization experiment and the one-dimensional sand pack experiment are conducted to investigate the influence of temperature on the foamy oil cold production process. According to the experimental results, it can be concluded that the temperature has great influence on foamy oil flow stage during the CHOP process. Therefore, it is necessary to study the optimal conversion timing of follow-up thermal recovery approaches after CHOP for the foamy extraheavy oil reservoir. Based on the analysis of the experimental results, the compositional foamy oil model is established by taking the effect of temperature into consideration. In the numerical model, the conversion timings of different thermal recovery approaches are investigated. The optimal conversion timings for cyclic steam stimulation (CSS) and steam flooding (SF) processes are the moments when the pressure drops to the pseudo-bubble point pressure. For the CSS method, excessive pressure cannot give full play to the production potential of CHOP stage; when the pressure is too low, it lacks enough energy to drive the heated crude oil to the wellbore. For the SF method, high pressure cannot fully release the latent heat of steam, and the content of dissolved gas (which will hinder the heat transfer) in oil phase is higher under high pressure, while the very low pressure leads to relatively high viscosity of crude oil; thus, the performance of the SF process becomes worse. For the SAGD process, the adverse effects of released solution gas in foamy extraheavy oil reservoir outweigh the positive effects. As a result, the CHOP period should be extended as long as possible to obtain a high recovery. In other words, the recovery process should be switched to the SAGD process at a relatively low formation pressure. The findings of this study could help for better understanding of the CHOP and post-CHOP thermal techniques for foamy extraheavy oil reservoirs, and it can provide guidance for reservoir engineers to make better use of the thermal recovery techniques to further improve the recovery performance of foamy extraheavy oil reservoirs.
\end{abstract}

\section{Introduction}

With the exhaustion of conventional oil resources, heavy oil is considered to be one of the most promising unconventional resources [1-5]. Large amount of heavy oil has been discovered worldwide, which accounts for approximately two-thirds of the global crude oil resources [6-9]. Heavy oil is characterized by its high content of asphaltenes and resins, which leads to a high viscosity. Generally, heavy oil is immobile under reservoir conditions [10-12]. As a result, thermal recovery approaches are often applied in the development of heavy oil reservoirs, specifically extraheavy oil reservoirs. However, for the foamy extraheavy oil reservoirs located in Orinoco Heavy Oil Belt at Venezuela, the cold heavy oil production (CHOP) method was applied in the initial stage of oilfield production using horizontal wells. Due to the mobility of the foamy oil flow, the CHOP method received unexpected success regardless of the high viscosity [13-15].

The foamy oil flow within the aforementioned extraheavy oil reservoir is the crucial factor in cold production 


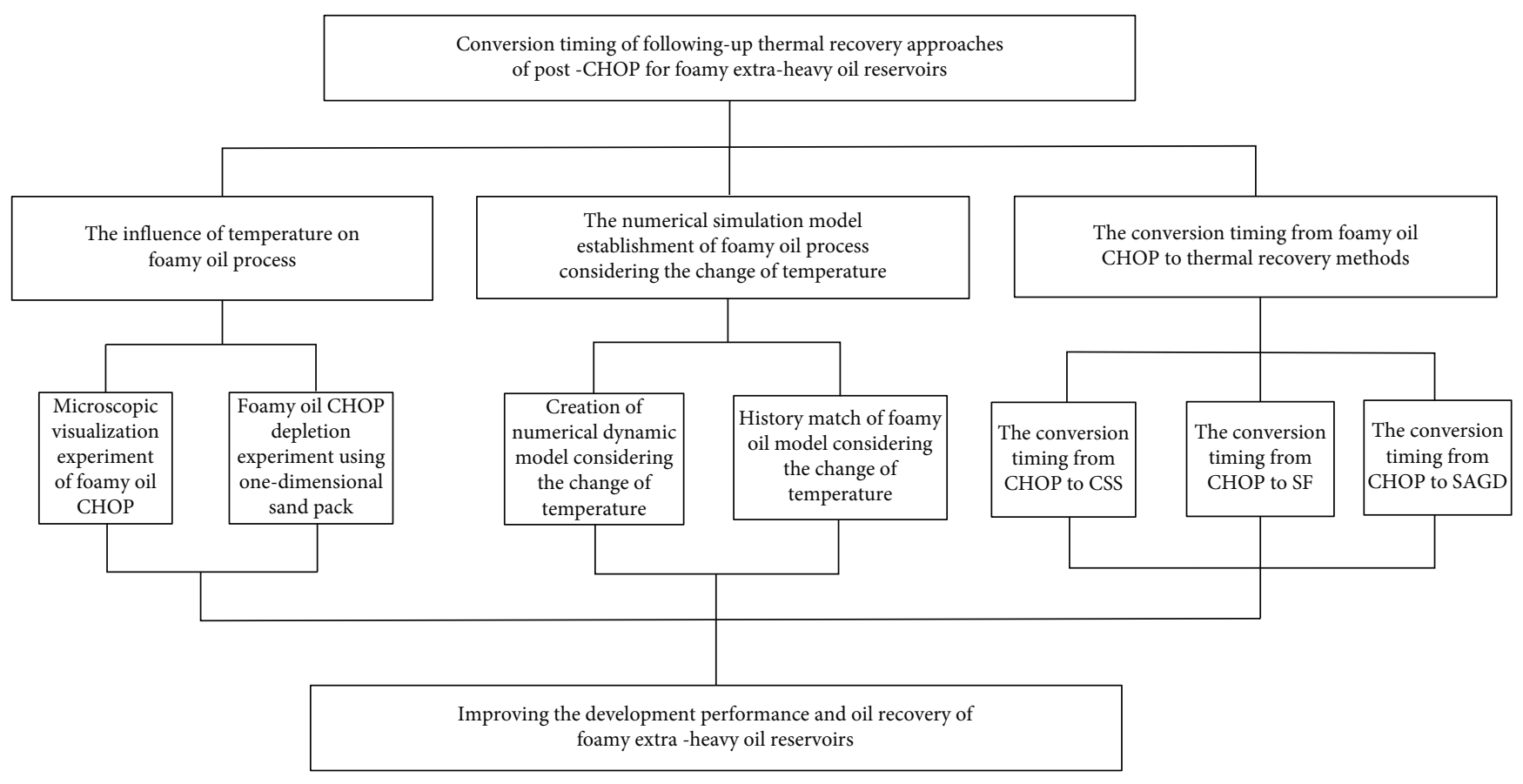

Figure 1: General sketch of this study.

technology [16-20]. Foamy oil flow refers to the gas-oil twophase flow in the stage of solution-gas drive in extraheavy oil reservoirs. The advantages of foamy oil flow are highlighted in three points: (1) high oil production, (2) low produced gas-to-oil ratio, and (3) low depletion rate of formation pressure [21]. However, one deficiency of applying CHOP technique in foamy extraheavy oil reservoir is the low recovery, which is about $10-12 \%$ [20]. Therefore, it is of great importance to apply follow-up thermal recovery approaches to further improve the oil recovery after the initial production stage of foamy extraheavy oil reservoirs. Different from traditional heavy oil reservoirs which are developed only by thermal recovery methods, foamy extraheavy oil reservoirs have a prior production stage (the CHOP process) before the thermal recovery. As a result, the conversion timing from CHOP to thermal recovery stage should be investigated to maximize the oil recovery.

The commonly used thermal recovery approaches in heavy oil or oil sand reservoirs include cyclic steam stimulation (CSS), steam flooding (SF), and steam-assisted gravity drainage (SAGD) technique. A substantial number of researches have been conducted in the application and optimization of the thermal recovery techniques in traditional heavy oil reservoirs [22-27]. However, the studies of thermal recovery techniques after $\mathrm{CHOP}$ stage in foamy extraheavy oil reservoirs are relatively few. Bao et al. [14] performed the numerical simulation study using CSS after CHOP stage in foamy extraheavy oil reservoirs. However, the conversion timing from CHOP to CSS was not taken into consideration. Coll et al. [28] showed that CSS, SF, SAGD, and other thermal recovery techniques were suitable for improving the recovery of foamy extraheavy oil reservoirs in Orinoco Oil Belt. In addition, the challenges encountered by the implementation of the above thermal recovery techniques were also mentioned in their study, which were mainly caused by the field surface engineering issues. Escobar et al. [29] proposed a semianalytical method to evaluate the followup thermal processes in the extraheavy oil reservoirs in Orinoco Oil Belt. Their research provided an on-field solution for the development of a giant extraheavy oil reservoir. Based on the previous analysis, none of the above studies systematically investigated the effect of the conversion timing in foamy extraheavy oil reservoirs. In addition, the effects of injected heat fluids were not incorporated in previous studies.

As shown in Figure 1, in this paper, both the experimental and numerical approaches are applied in the investigation of follow-up thermal recovery methods after CHOP in the foamy extraheavy oil reservoirs. Based on the experimental results, we build the foamy-oil compositional model with the consideration of temperature effect. The conversion timings of CSS, SF, and SAGD processes after CHOP are studied by employing the compositional model. This paper is structured as follows: First, the experimental section is setup. Then, the base numerical simulation model is completed using the commercial CMG [30] software, according to the typical foamy extraheavy oil properties and operation parameters. Next, the conversion timing research of following up thermal recovery approaches after $\mathrm{CHOP}$ are conducted. Finally, the results are summarized and discussed.

\section{Physical Experiments}

2.1. Experimental Materials. The dead oil analyzed in experiments was collected from Carabobo region in Orinoco Heavy Oil Belt, Venezuela. The viscosity of the dead oil is $14488 \mathrm{cP}$. The produced gas consists of $\mathrm{CO}_{2}$ and $\mathrm{CH}_{4}$, with the mole fractions of $13 \%$ and $87 \%$, respectively. The 


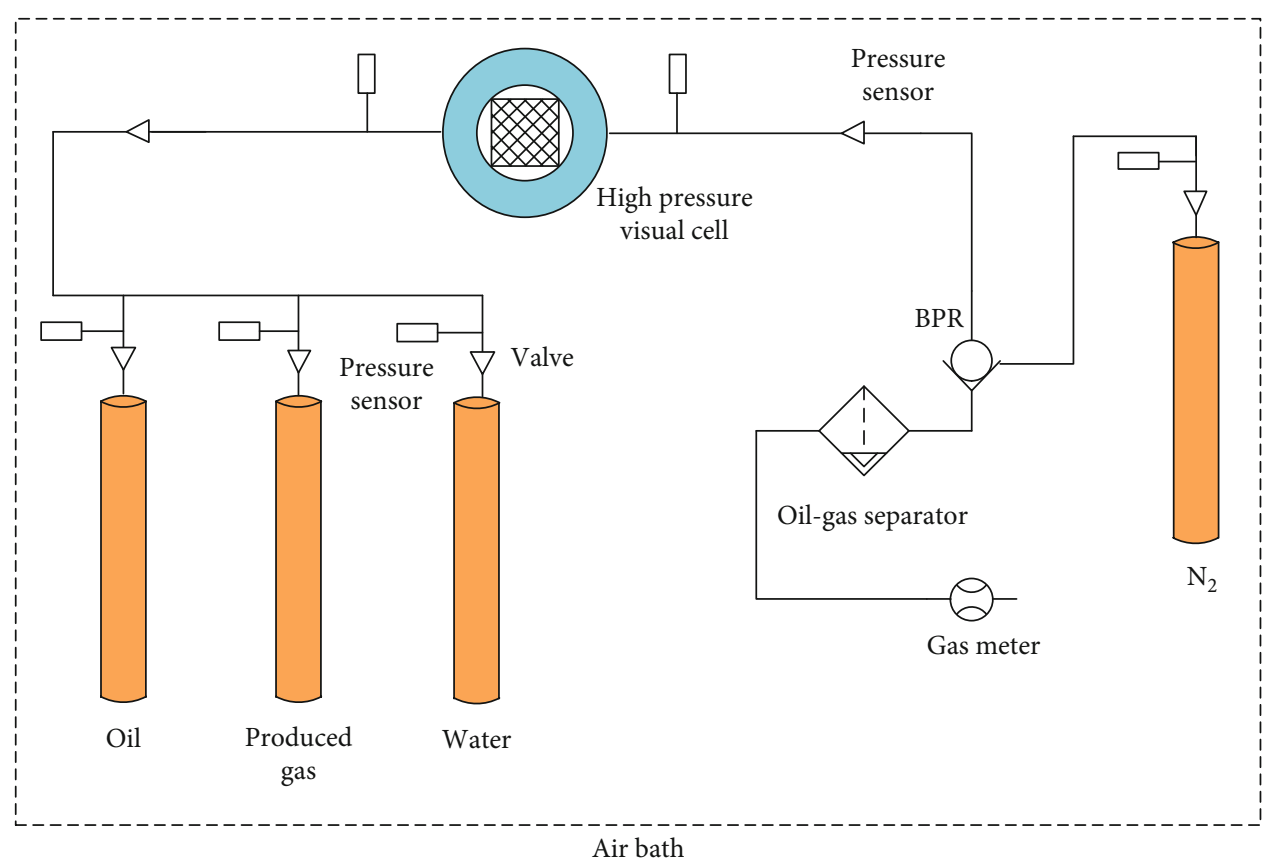

FIGURE 2: Schematic illustration of the microscopic visualization experimental apparatus.

reservoir temperature is set as $54^{\circ} \mathrm{C}$. The initial solution gasoil ratio is $16 \mathrm{sm}^{3} / \mathrm{m}^{3}$. The bubble point pressure of reservoir is $5.6 \mathrm{MPa}$.

\subsection{Experimental Designs}

2.2.1. Microscopic Visualization Experiment. The schematic illustration of the microscopic visualization experimental apparatus is shown in Figure 2. The experimental apparatus mainly consists of the microglass etching model (size: 50 $\mathrm{mm} \times 50 \mathrm{~mm}$ and channel diameter: $40 \sim 50 \mu \mathrm{m})$, the digital microscopic camera system, and the ISCO pump. The experimental procedures were shown as follows: (1) the live oil was added to the intermediate container; (2) the micromodel was vacuumized and saturated with distilled water; (3) the back pressure was set to $8 \mathrm{MPa}$, and the water within the micromodel was displaced by live oil; (4) the back pressure was reduced at the rate of $10 \mathrm{kPa} / \mathrm{min}$ by controlling the nitrogen pressure via the back pressure valve, and the entire experimental process of dissolved gas drive was recorded by the digital microscopic camera system. A series of experiments following the above procedures were conducted at $54^{\circ} \mathrm{C}, 75^{\circ} \mathrm{C}, 85^{\circ} \mathrm{C}, 100^{\circ} \mathrm{C}, 120^{\circ} \mathrm{C}$, and $150^{\circ} \mathrm{C}$, respectively.

2.2.2. Pressure-Depletion Experiment. The experimental devices of pressure-depletion experiment are shown in Figure 3. The sand pack used in this study is characterized by the length of $60 \mathrm{~cm}$ and diameter of $2.54 \mathrm{~cm}$, and 80 100 mesh quartz sand is selected as the base material to fulfill the sand pack.

The experimental procedures are shown as follows: (1) the live oil was prepared based on the aforementioned reservoir conditions; (2) the sand pack was vacuumized for 4 hours and then saturated with water. The permeability and porosity of the sand pack were measured; (3) the back pres- sure was set to $8 \mathrm{MPa}$, and the water within the sand pack was displaced by the live oil until there is no water produce. The initial oil saturation could be calculated; (4) with the pressure drop rate of $10 \mathrm{kPa} / \mathrm{min}$, the back pressure was gradually decreased until no oil and gas were produced. The changes of oil production, gas production, and pressure were recorded in the whole depletion process. A series of experiments following the above procedures were conducted in the thermostatic chamber at $54^{\circ} \mathrm{C}, 75^{\circ} \mathrm{C}, 85^{\circ} \mathrm{C}, 100^{\circ} \mathrm{C}$, $120^{\circ} \mathrm{C}$, and $150^{\circ} \mathrm{C}$, respectively.

\section{Results and Discussion}

3.1. Microscopic Seepage Characteristics of Foamy Oil Flow. The microscopic seepage images of cold production process at temperatures of $54^{\circ} \mathrm{C}, 100^{\circ} \mathrm{C}$, and $150^{\circ} \mathrm{C}$ are shown in Figures 4-6. It can be observed from Figures 4 and 5 that the microscopic seepage processes of foamy oil flow at $54^{\circ} \mathrm{C}$ and $100^{\circ} \mathrm{C}$ are similar, which can be divided into three stages:

(1) Single-Phase Flow Stage. When the pressure is higher than the bubble point pressure, there is no gas escaped from the crude oil and therefore, the single-phase flow dominates.

(2) Foamy Oil Flow Stage. When the pressure is lower than the bubble point pressure, the gas gradually escapes from the crude oil and exists as small bubbles in the crude oil. The bubbles facilitate the flow of the crude oil to form the seepage state of the foamy oil flow. With the increase of foam volume, phenomena including deformation, coalescence, and splitting could be observed at the temperatures of $54^{\circ} \mathrm{C}$ and $100^{\circ} \mathrm{C}$. Hence, in the foamy oil flow 


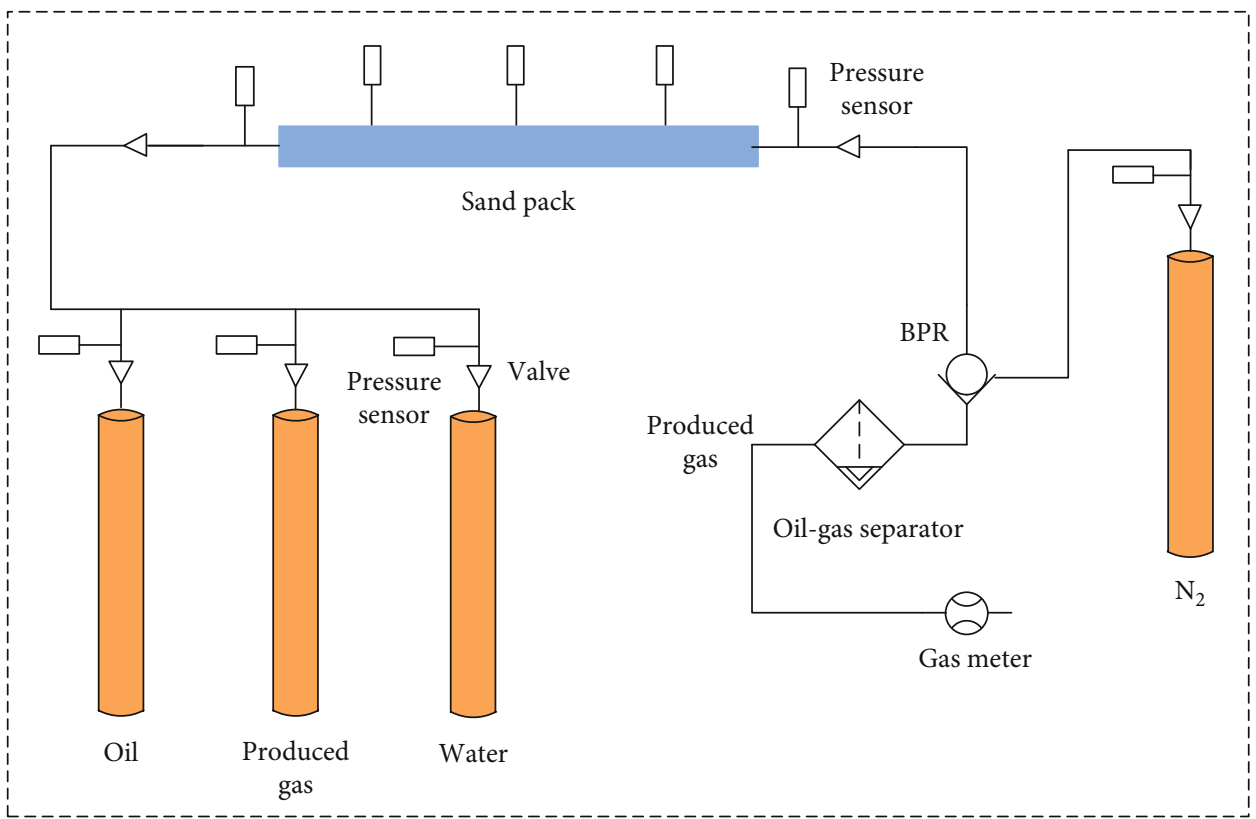

Air bath

FIGURE 3: Schematic diagram of the pressure depletion experiment.

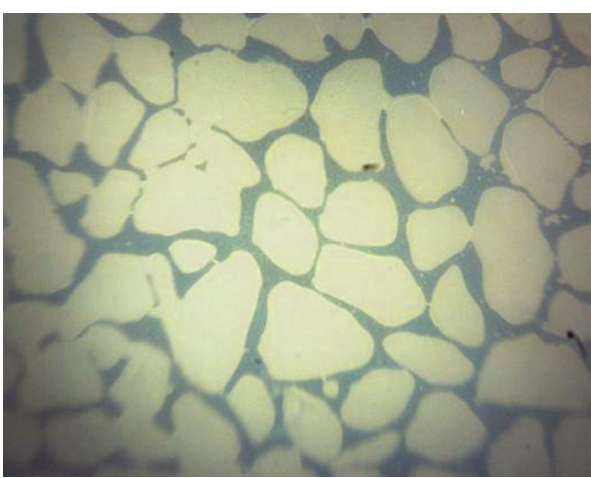

(a) $6.2 \mathrm{MPa}$

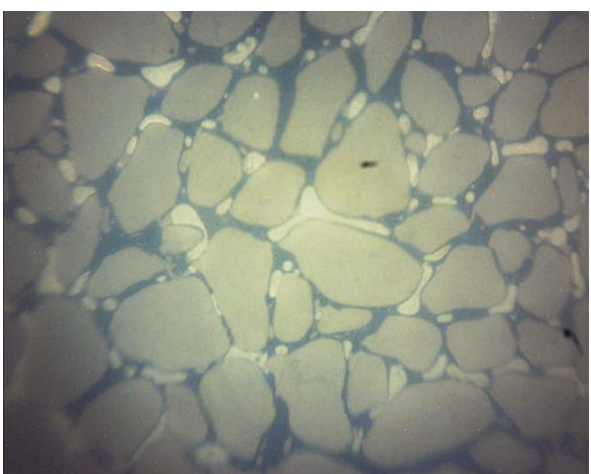

(b) $4.5 \mathrm{MPa}$

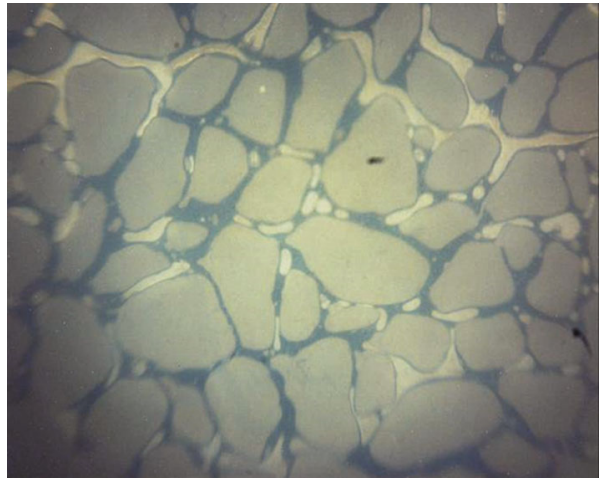

(c) $1.0 \mathrm{MPa}$

FIgURE 4: Microscopic seepage images of depletion process at the temperatures of $54^{\circ} \mathrm{C}$.

stage, the gas bubbles disperse in the crude oil, which slows down the formation of the continuous gas phase and the occurrence of gas channeling.
(3) Oil and Gas Two-Phase Flow Stage. As the pressure further decreases, more dissolved gas escapes from the oil phase, and the dispersed bubbles gradually 


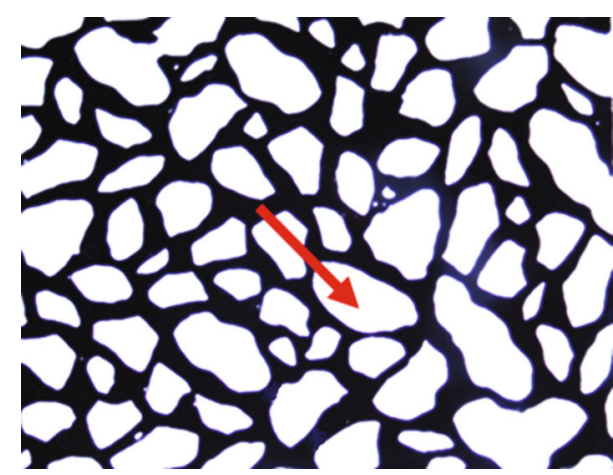

(a) $6.2 \mathrm{MPa}$

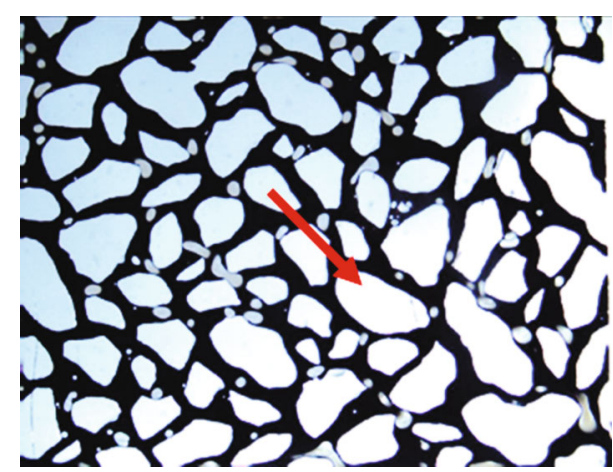

(b) $5.0 \mathrm{MPa}$

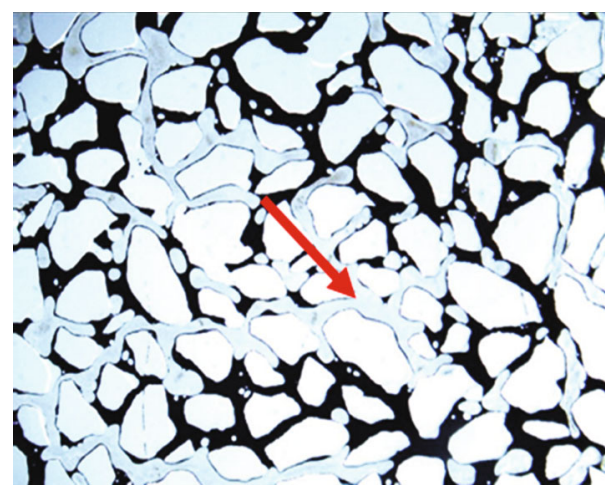

(c) $3.0 \mathrm{MPa}$

Figure 5: Microscopic seepage images of depletion process at the temperatures of $100^{\circ} \mathrm{C}$.

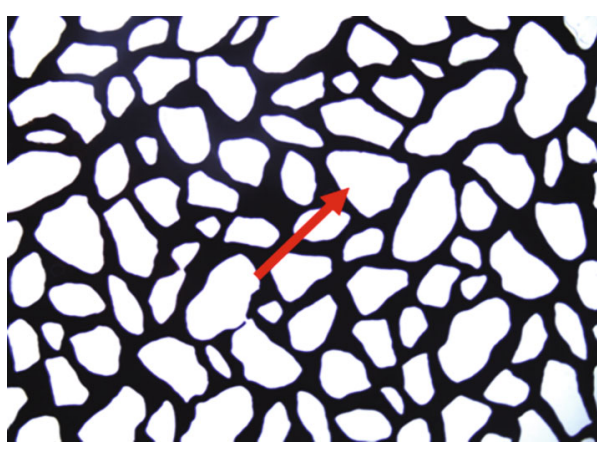

(a) $6.2 \mathrm{MPa}$

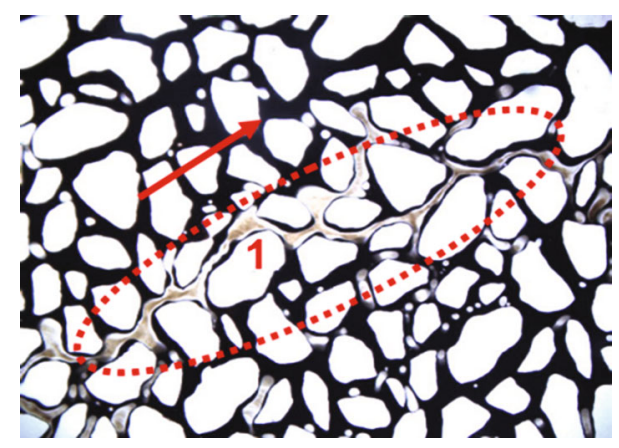

(b) $5.0 \mathrm{MPa}$

Figure 6: Microscopic seepage images of depletion process at the temperatures of $150^{\circ} \mathrm{C}$.

gather together to form the continuous phase. When the pressure is relatively low, the interfacial tension between oil and gas phase is high and the foamy oil system is unstable. As the pressure further decreases, the bubbles are prone to coalesce, which leads to the development of continuous gas phase. Eventually, the oil and gas two-phase seepage state forms.

Different from the microscopic seepage characteristics of foamy oil flow at $54^{\circ} \mathrm{C}$ and $100^{\circ} \mathrm{C}$, there is no obvious foamy oil flow stage observed at the temperature of $150^{\circ} \mathrm{C}$. As shown in Figure 6, when the pressure is lower than the bubble point pressure, the gas quickly escapes from the crude oil and forms the continuous gas phase, without the phenomena of bubble coalescence and splitting. As a result, the single-phase flow stage directly switches to the oil-gas two-phase flow stage. The reasons are twofolded. For one thing, the higher the temperature, the lower the viscosity of the crude oil. The dispersion theory shows that the viscosity of the continuous phase has a great impact on the coalescence, sedimentation, and drainage of the dispersed phase, and it plays an important role in the stability of the dispersion system. If the viscosity of crude oil is low, the bubbles are easy to break through the oil film and coalesce, which reduces the stability of the foamy oil system. For another, the interfacial tension between oil and 


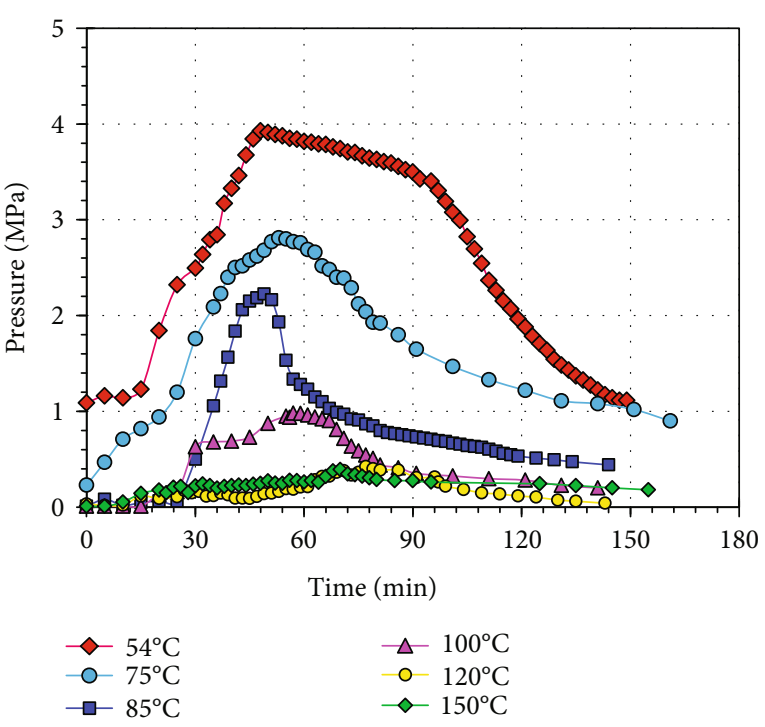

FIgURE 7: Variation of production differential pressure with time.

gas increases with the increase of temperature, which means that the higher temperature leads to an unstable foamy oil system. As a result, the dispersed gas bubbles are easy to form the continuous gas phase.

3.1.1. Characteristics of Foamy Oil Displacement. Figure 7 shows the variation of production differential pressure with time in pressure depletion experiment at different temperature conditions. It can be observed from Figure 7 that the pressure difference first increases and then decreases during the depletion process, and the pressure difference decreases sharply when the temperature is high. This is mainly because the viscosity of heavy oil is sensitive to temperature. With the increase of temperature, the viscosity of crude oil decreases dramatically.

The variations of oil production rate and gas production rate with pressure are shown in Figures 8 and 9. The depletion process can be divided into three stages:

(1) Single-Phase Flow Stage (Pressure Ranging from the Initial Pressure $(8.0 \mathrm{MPa})$ to the Bubble Point Pressure). The pressure in this stage is higher than the bubble point pressure, and no gas is produced. The oil produced in this stage is due to the expansion of crude oil as the pressure decreases. As a result, the oil displacement efficiency in this stage is very low (only about 1-2\%) and the produced gas-oil ratio is equal to the initial solution gas-oil ratio.

(2) Foamy Oil Seepage Stage (Pressure Ranging from the Bubble Point Pressure to the Pseudo-Bubble Point Pressure). At this stage, the pressure is lower than the bubble point pressure, and the gas is separated from the crude oil and flows with the crude oil in a dispersed phase state. It can be observed from Figure 8 that the oil production rate increases rapidly at this stage, which indicates that the bubbles in the foamy oil could increase the elastic energy of the sys-

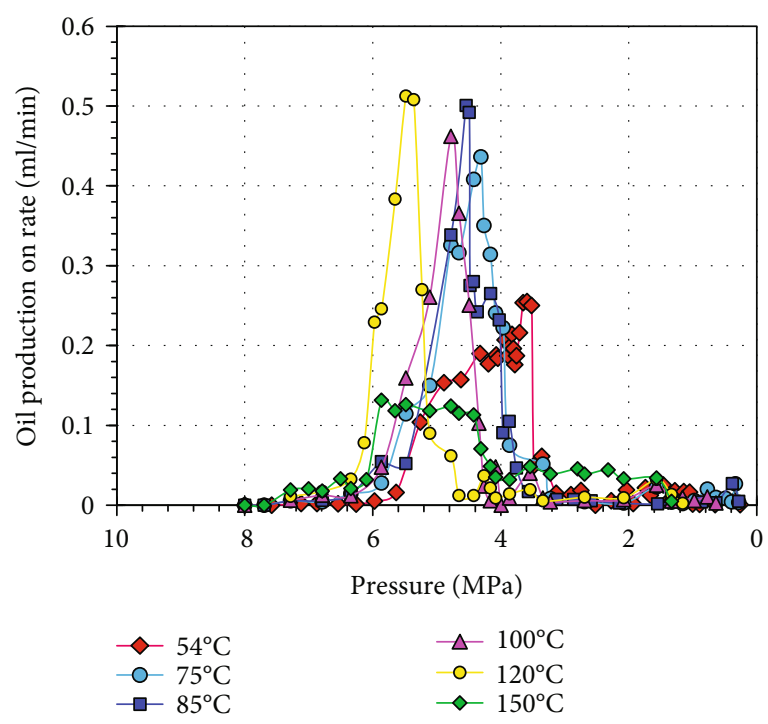

FIGURE 8: Variation of oil production rate with pressure.

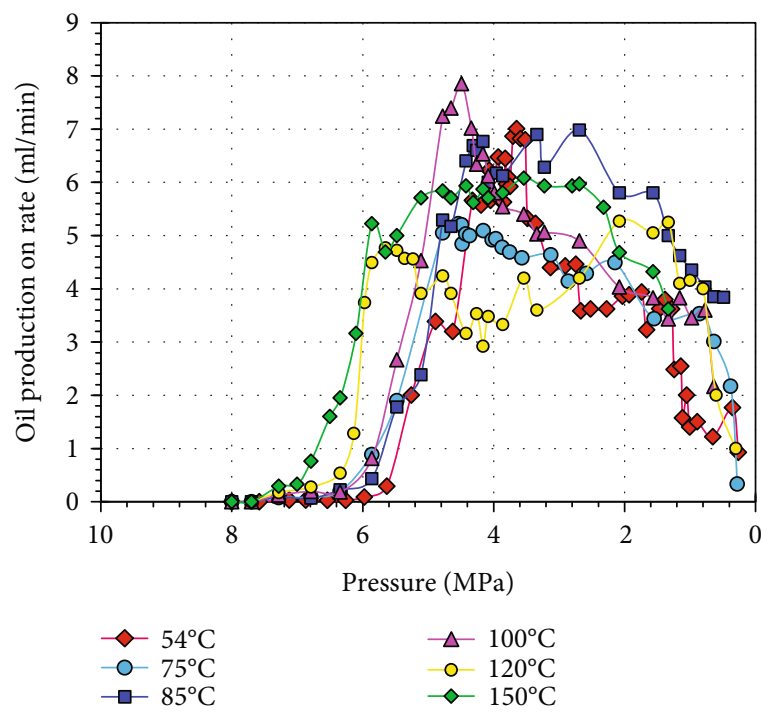

FIGURE 9: Variation of gas production rate with pressure.

tem. The gas-oil ratio at this stage is kept at a low level. The main reason is that the gas exists in the form of the dispersed phase, and the oil film between the bubbles reduces the mobility of the gas phase which limits the release of gas. The maximum oil production rate shows up at higher pressure as temperature increases, which means that the pseudobubble point pressure gradually increases with the increase of temperature. The maximum gas production rate shows up at higher pressure as temperature increases, which is due to the decrease of solution gas-oil ratio at high temperature conditions.

(3) Continuous Gas Phase Stage (Pressure Lower than the Pseudo-Bubble Point Pressure). At this stage, the dispersed gas changes to the continuous phase and the system is in the oil and gas two-phase flow state. 
TABLE 1: The parameters of numerical simulation model.

\begin{tabular}{lcc}
\hline Item & Unit & Value \\
\hline Reservoir pressure & $\mathrm{kPa}$ & 8550 \\
Reservoir temperature & ${ }^{\circ} \mathrm{C}$ & 54 \\
Average porosity & Fraction & 0.32 \\
Average permeability & $\mathrm{mD}$ & 6500 \\
Dead oil viscosity & $\mathrm{cP}$ & 26490 \\
Solution gas to oil ratio & $\mathrm{m}^{3} / \mathrm{m}^{3}$ & 15.84 \\
Bubble point pressure & $\mathrm{kPa}$ & 6150 \\
Pseudo-bubble point pressure & $\mathrm{kPa}$ & 3500 \\
Live oil viscosity & $\mathrm{cP}$ & 3000 \\
\hline
\end{tabular}

Since the mobility of the continuous gas phase is higher than the mobility of the oil phase, the oil production rate is significantly reduced while the gas production rate maintains a high value. In this stage, serious gas channeling occurs and the produced gasoil ratio increases rapidly.

\section{Numerical Simulation}

4.1. Simulation Model. After the steam is injected into the formation, the temperature of the steam is unevenly distributed. The temperature of the steam front in contact with the crude oil is the lowest while the temperature in the area closer to the steam injection well is the highest. Based on the foamy oil experiments at different temperatures in the previous part, it can be concluded that the temperature has a great influence on the oil displacement performance of foamy oil flow.

Herein, a compositional foamy-oil model considering the effect of temperature was established in order to investigate the conversion timing of follow-up thermal recovery approaches of post-CHOP period for foamy extraheavy oil reservoirs.

The experimental results of foamy oil depletion experiment were used in the numerical simulation settings. The basic parameters of $1 \mathrm{D}$ model are listed in Table 1. For CHOP stage, the foamy oil model includes three forms of gas to represent nonequilibrium foamy oil behavior through bubble formation and growth during gas release process:

(a) The Solution Gas. It is dissolved in the oil phase;

(b) The Dispersed Gas. It is released from the oil due to the pressure drop, existing in dispersed bubbles;

(c) The Free Gas. It is representing the continuous gas phase.

The foamy oil simulation model simulates the transformation of the three gas states using nonequilibrium reactions. Two reactions are defined with their own kinetics:

Reaction 1: solution gas $\rightarrow$ dispersed gas: $X_{1}=F_{1} \times([$ $\left.\left.G_{\text {sol.eq }}\right]-\left[G_{\text {sol }}\right]\right)$, representing the formation of dispersed bubbles.
Reaction 2: dispersed gas $\rightarrow$ free gas: $X_{2}=F_{2} \times\left[G_{\text {disp }}\right]$, representing the growth and collapse of dispersed bubbles.

The fitting results are shown in Figure 10 by adjusting the values of $F_{1}$ and $F_{2}$ to fit the foamy oil depletion experiment under different temperatures of $54^{\circ} \mathrm{C}, 85^{\circ} \mathrm{C}$, and $120^{\circ} \mathrm{C}$, respectively.

Using the fitted model, the conversion timings to CSS, $\mathrm{SF}$, and SAGD after CHOP of foamy extraheavy oil reservoir are studied.

4.2. CSS after CHOP. CSS is a thermal recovery technique which has been successfully applied in many extraheavy oil reservoirs. Similar to CHOP technique, CSS is also a technique which relies on formation pressure to provide energy for oil recovery. Therefore, it is necessary to study the conversion timing of CSS for foamy extraheavy oil reservoirs.

The recovery of CHOP and follow-up CSS techniques are studied at different conversion timings (when the formation pressure decreases to $6.2 \mathrm{MPa}, 4.8 \mathrm{MPa}, 3.4 \mathrm{MPa}$, and 2.0 $\mathrm{MPa}$, respectively). The related simulation conditions are set as follows: at the CHOP stage, the maximum oil production rate is $200 \mathrm{~m}^{3} / \mathrm{d}$, and the maximum production pressure drop is $1.4 \mathrm{MPa}$; at the CSS stage, the bottom-hole steam quality is 0.7 , the maximum injection pressure of steam is $8.3 \mathrm{MPa}$, the maximum injection rate of steam is $200 \mathrm{~m}^{3} / \mathrm{d}$, the soaking time is 10 days, and the maximum liquid production rate is $200 \mathrm{~m}^{3} / \mathrm{d}$. When the oil production rate at CSS stage drops below the oil production rate of CHOP stage, the production will switch to a new CSS cycle. The economic limit of oil-steam ratio is set as 0.4.

As shown in Table 2 and Figure 11, the simulation results indicate that the recovery factor and the cumulative oil-steam ratio (cOSR) at the CSS stage gradually decrease with the decreasing of the converting formation pressure. When the converting formation pressure is lower than 3.4 MPa, the recovery factor of CSS stage decreases significantly with the decrease of converting formation pressure. Furthermore, the effect of conversion timing on the overall performance of the entire recovery process is analyzed. The results show that the optimal conversion timing lies in the condition that the formation pressure is the pseudo-bubble point pressure. As shown in Table 2, the overall recovery factor of entire process is the highest when the conversion time is about $3.4 \mathrm{MPa}$, which is near the pseudo-bubble point pressure. In addition, the cOSR of such case is also within the acceptance range. The reason is that the foamy oil displacement mechanism is fully leveraged, and the CSS process is still efficient in enhancing oil recovery, although the formation pressure is decreased to some extent.

For the CSS method, excessive pressure cannot give full play to the production potential of CHOP stage. When the formation pressure is too low, the heated crude oil cannot flow to the wellbore.

4.3. SF after CHOP. Steam flooding (SF) technique can effectively improve the recovery of heavy oil reservoirs. But for SF with horizontal wells, the problems of steam breakthrough and steam overlying can significantly limit the application 


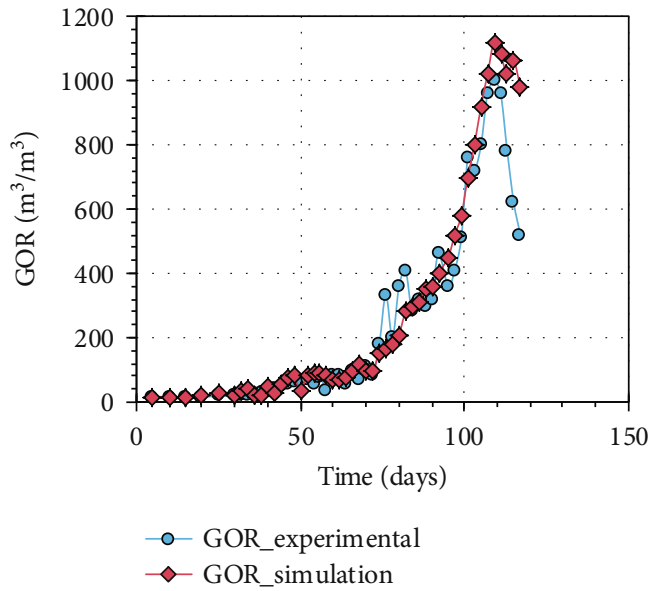

(a) $54^{\circ} \mathrm{C}$

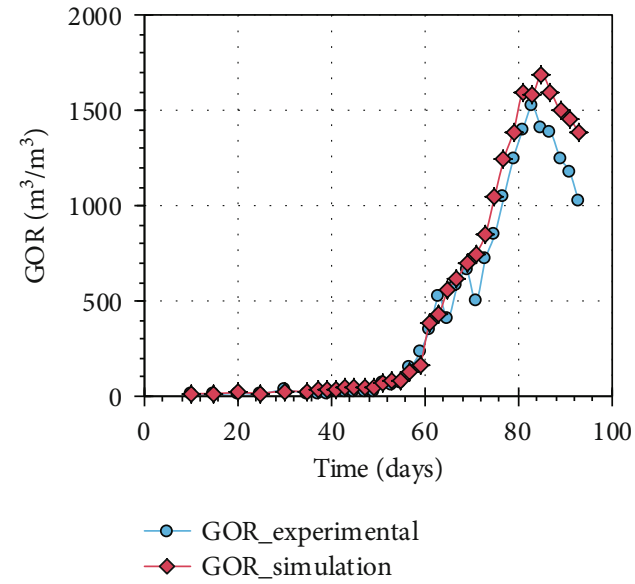

(b) $85^{\circ} \mathrm{C}$

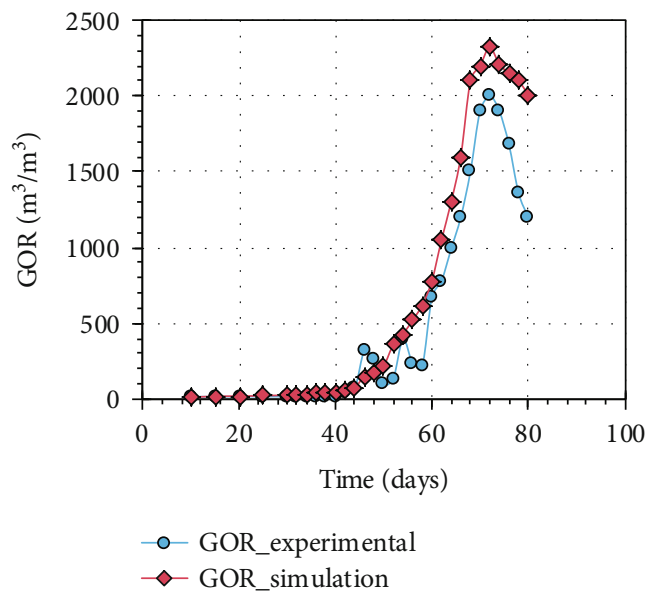

(c) $120^{\circ} \mathrm{C}$

Figure 10: The history matching results of numerical simulation model.

TABLE 2: Simulation parameters and results of CSS with different conversion pressure.

\begin{tabular}{|c|c|c|c|c|c|c|}
\hline $\begin{array}{l}\text { Conversion pressure } \\
(\mathrm{MPa})\end{array}$ & $\begin{array}{l}\text { Horizontal well } \\
\text { spacing }(\mathrm{m})\end{array}$ & $\begin{array}{l}\text { Cycles of } \\
\text { CSS }\end{array}$ & $\begin{array}{c}\text { Oil recovery factor of } \\
\text { CHOP }(\%)\end{array}$ & $\begin{array}{c}\text { Oil recovery factor of } \\
\text { CSS (\%) }\end{array}$ & $\begin{array}{l}\text { Oil recovery } \\
\text { factor }(\%)\end{array}$ & $\begin{array}{c}\text { Cumulative } \\
\text { OSR }\end{array}$ \\
\hline 6.2 & 300 & 14 & 1.2 & 12.8 & 14 & 0.88 \\
\hline 4.8 & 300 & 13 & 2.3 & 12 & 14.3 & 0.75 \\
\hline 3.4 & 300 & 12 & 3.6 & 11.6 & 15.2 & 0.62 \\
\hline 2.0 & 300 & 8 & 5.6 & 8 & 13.6 & 0.55 \\
\hline
\end{tabular}

of SF $[31,32]$. As a result, the SF with both horizontal and vertical wells is adopted in this study.

In this study, eight vertical steam injection wells and one horizontal production well are utilized in the SF process. The recovery of CHOP and follow-up SF are studied at different conversion timings (when the formation pressure decreased to $6.2 \mathrm{MPa}, 4.8 \mathrm{MPa}, 3.4 \mathrm{MPa}$, and $2.0 \mathrm{MPa}$, respectively). The related simulation conditions are set as follows: the horizontal well spacing is $50 \mathrm{~m}$, and the steam quality is 0.7 ; the vertical distance between steam injection well and production well is $9 \mathrm{~m}$; when the steam-oil ratio reaches the value of 8 , the simulation terminates.
The simulation results are shown in Table 3 and Figure 12. It can be concluded that both the oil recovery factor of the CHOP stage and the entire process increase with the decrease of conversion pressure. However, when the conversion pressure is $3.4 \mathrm{MPa}$, the recovery factor of SF stage reaches the highest value.

Figure 13 presents the 2D fields with different properties, which include temperature, gas mole fraction, and oil viscosity under different conversion times. It can be observed from the temperature field that the heated range is enlarged when the conversion pressure decreases. The main reason is that the content of solution gas decreases the reservoir pressure 


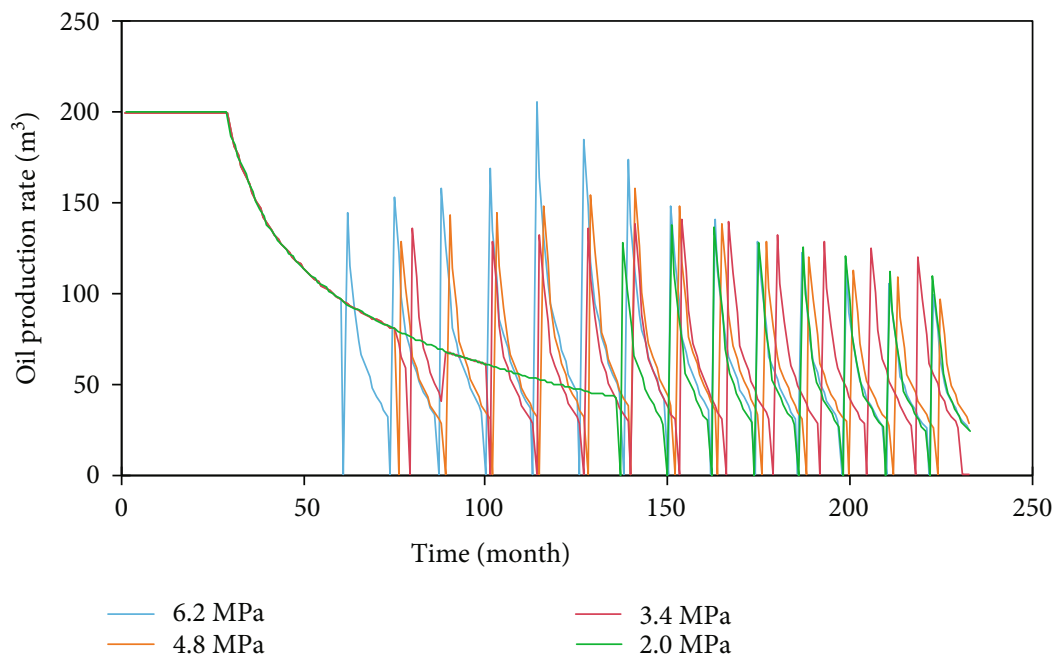

FIGURE 11: Oil production rate of CSS under different conversion timings.

TABLE 3: Simulation parameters and results of SF with different conversion pressure.

\begin{tabular}{|c|c|c|c|c|c|}
\hline $\begin{array}{l}\text { Conversion pressure } \\
(\mathrm{MPa})\end{array}$ & $\begin{array}{l}\text { Horizontal well spacing } \\
\text { (m) }\end{array}$ & $\begin{array}{l}\text { Oil recovery factor of } \\
\text { CHOP }(\%)\end{array}$ & $\begin{array}{l}\text { Oil recovery factor of SF } \\
(\%)\end{array}$ & $\begin{array}{l}\text { Oil recovery factor } \\
(\%)\end{array}$ & $\begin{array}{c}\text { Cumulative } \\
\text { OSR }\end{array}$ \\
\hline 6.2 & 50 & 1.9 & 26.9 & 28.8 & 0.175 \\
\hline 4.8 & 50 & 3.0 & 26 & 29.0 & 0.175 \\
\hline 3.4 & 50 & 4.0 & 27.3 & 31.3 & 0.207 \\
\hline 2.0 & 50 & 6.2 & 25.8 & 32.0 & 0.202 \\
\hline
\end{tabular}

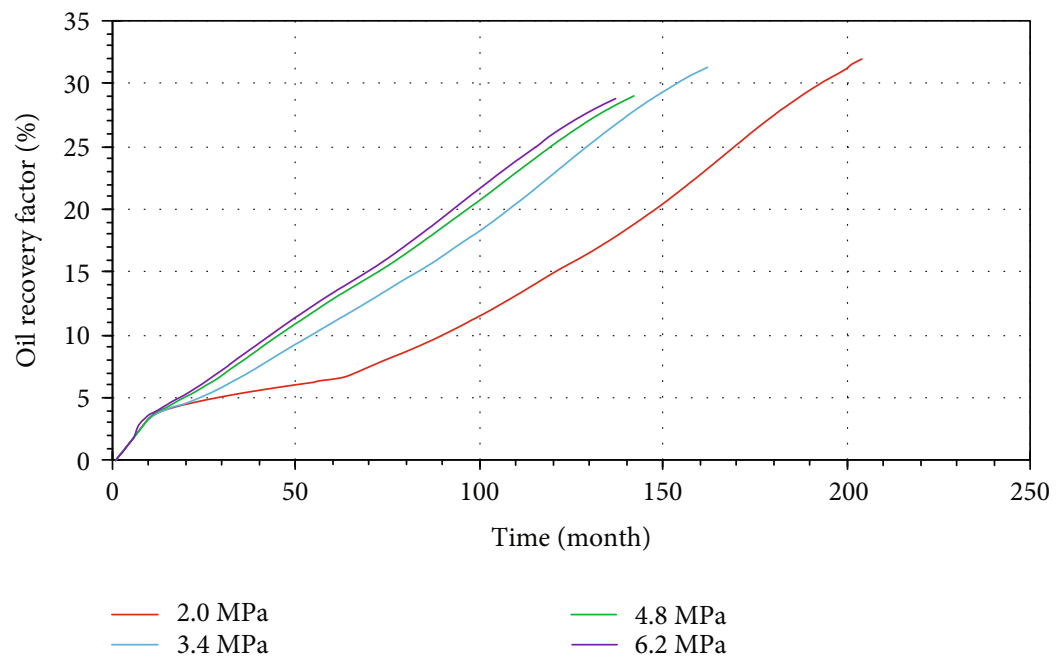

FIgURE 12: Oil recovery factor curves under different conversion timings.

decreases, which can be observed from the field of gas mole fraction. The released solution gas, a kind of noncondensate gas, can hinder the heat transfer of steam chamber. In addition, it can be observed from the field of oil viscosity that, with the decrease of reservoir pressure, the oil viscosity increases and the steam flow rate (pink arrows) from injector to producer decreases. When the reservoir pressure decreases to $2.0 \mathrm{MPa}$ (the oil viscosity is highest among the cases), the amount of steam flowing downward is reduced and the steam overlying phenomenon becomes obvious.
Therefore, there is an equilibrium point which can balance the influence of oil viscosity and the content of solution gas at the conversion timing. As a result, the optimal conversion timing is the pressure near the pseudo-bubble point pressure. Herein, the best conversion time for SF is the moment when the formation pressure drops to 3.4 MPa.

4.4. SAGD after CHOP. In the process of CHOP of foamy extraheavy oil reservoir, as the formation pressure drops, the viscosity of crude oil and the solution gas-oil ratio 
Conversion pressure of $6.2 \mathrm{MPa}$

Temperature (F)

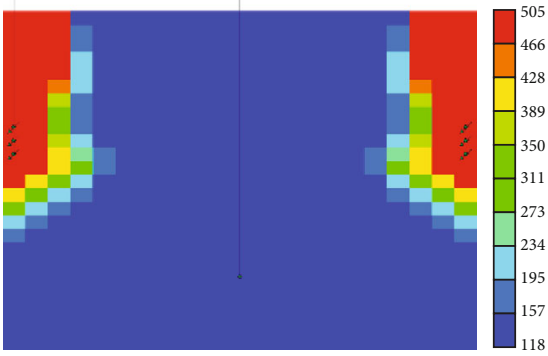

Temperature (F)

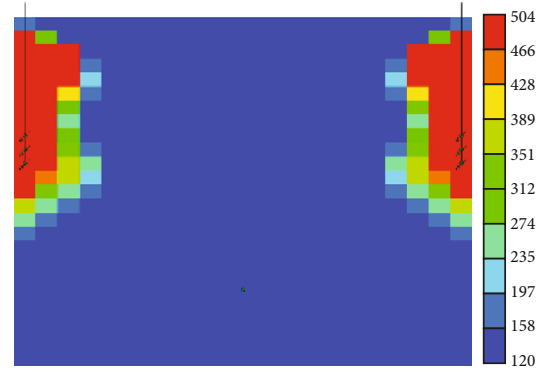

Temperature (F)

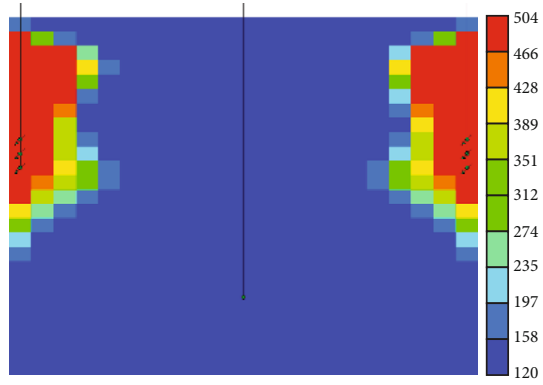

Temperature (F)

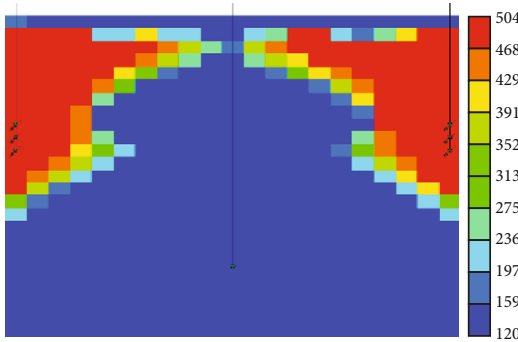

(a)
Gas mole fraction (SolnGas 1)

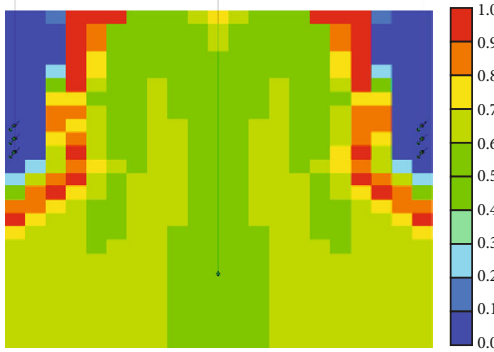

Conversion pressure of $4.8 \mathrm{MPa}$

Gas mole fraction (SolnGas 1)

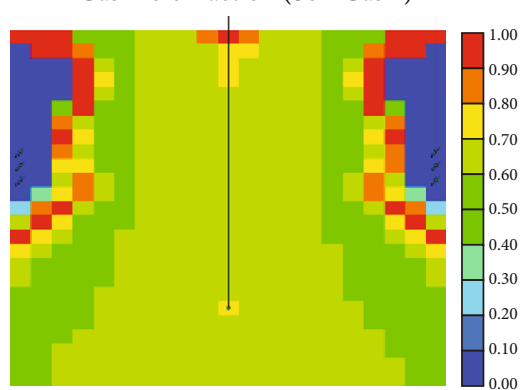

Conversion pressure of $3.4 \mathrm{MPa}$

Gas mole fraction (SolnGas 1)

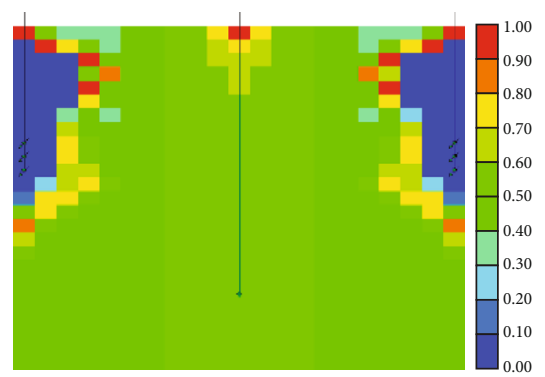

Conversion pressure of $2.0 \mathrm{MPa}$

Gas mole fraction (SolnGas 1)

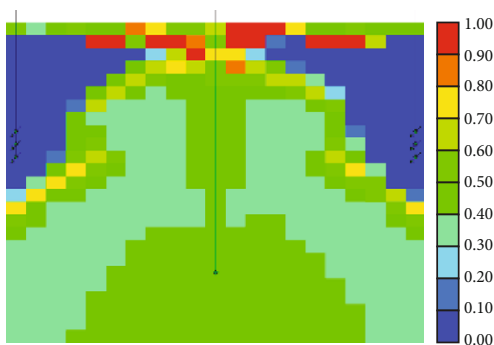

(b)

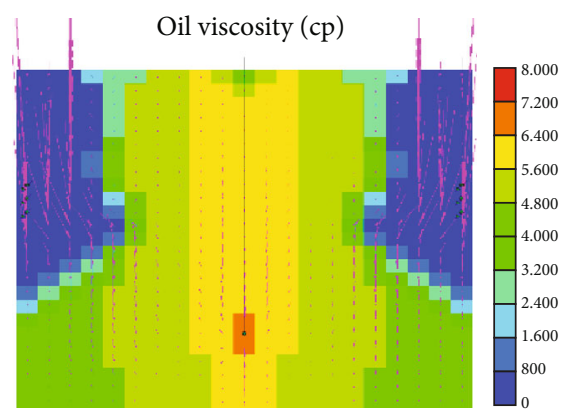

Oil viscosity (cp)

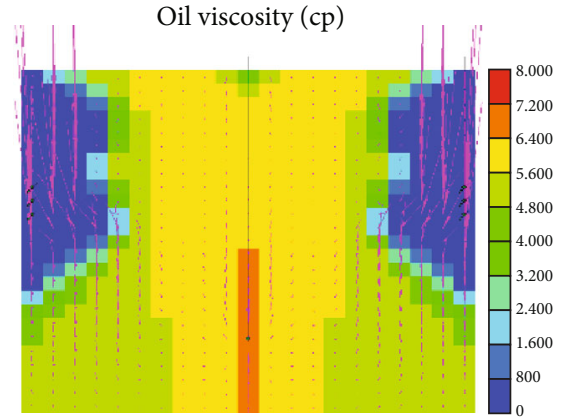

Oil viscosity $(\mathrm{cp})$
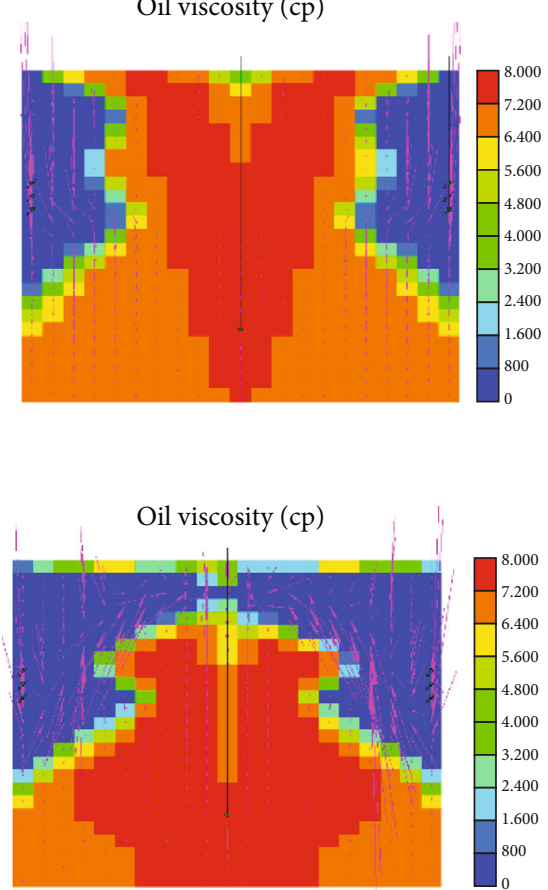

(c)

Figure 13: The 2D fields with different properties under different conversion timings.

change accordingly. Thus, it is necessary to determine the optimal timing to switch from CHOP to SAGD. In this section, the performance of SAGD process under different initiating timing is investigated. Firstly, the $\mathrm{CHOP}$ technique is adopted in foamy extraheavy oil reservoir. Then, the follow-up SAGD technique is employed when the formation pressure drops to $4 \mathrm{MPa}, 3 \mathrm{MPa}$, and $2 \mathrm{MPa}$, respectively.

Figure 14(a) shows that the lower the formation pressure at conversion time, the longer the duration of CHOP. In addition, the higher the recovery factor of the entire process, 


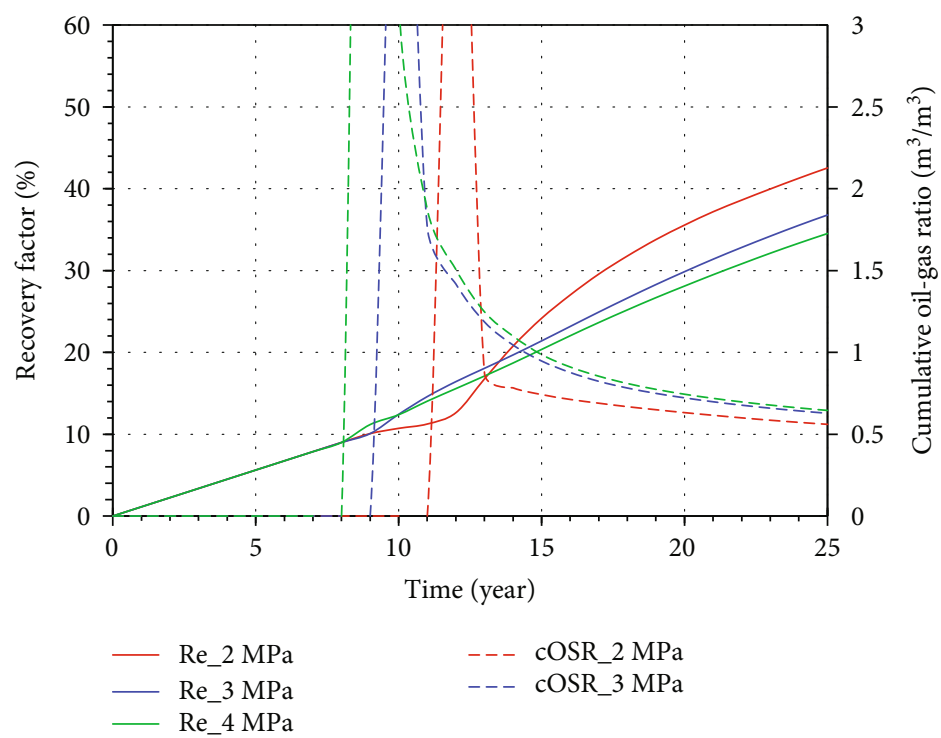

(a)

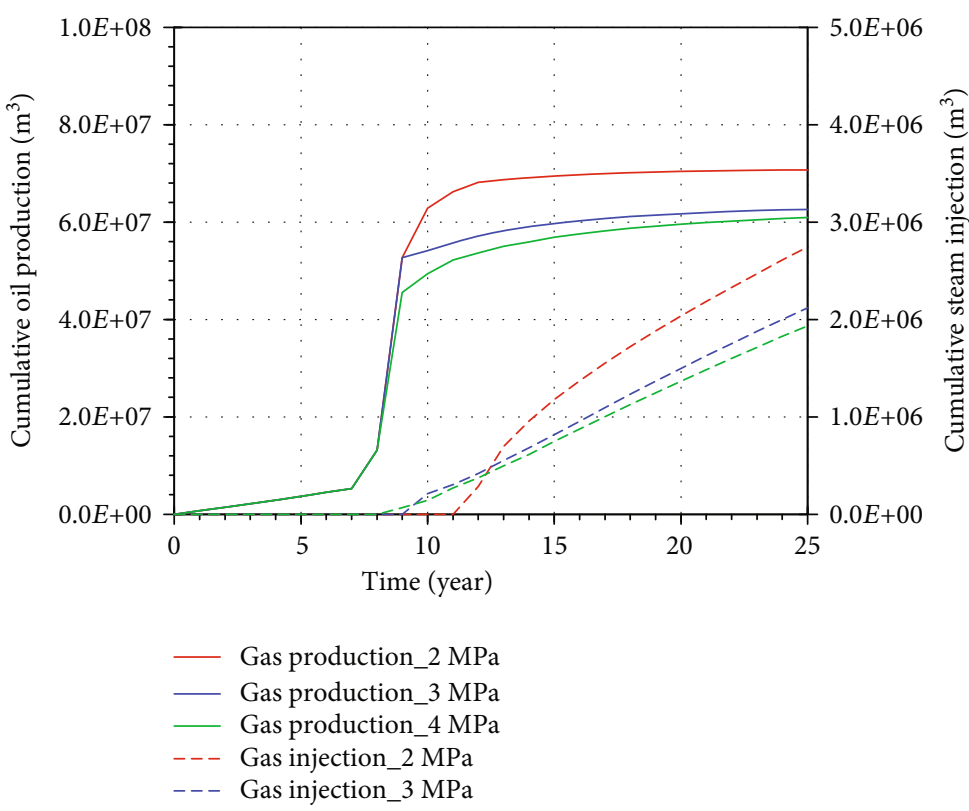

(b)

FIGURE 14: SAGD performance under different conversion timings: (a) recovery factor and cumulative oil steam ratio; (b) cumulative steam injection volume and gas production volume.

the lower the cumulative oil-steam ratio. The reason is that more solution gas will be released from the oil phase under the condition of low formation pressure. Thus, when the CHOP stage is switched to the SAGD stage, only a small amount of solution gas exists in the oil phase. The remaining solution gas is a kind of noncondensable gas, which plays two roles in the SAGD process. On the one hand, the remaining solution gas hinders the process of heat transfer and affects the expansion of steam chamber. On the other hand, it reduces the heat loss from steam chamber to the cap rock, which is beneficial to the SAGD process.

Figure 15 shows the mole fraction distribution of solution gas in different development stages of the SAGD pro- cess under different formation pressure conditions at the conversion time. The steam chamber consists of two parts. The blue area where the mole fraction of solution gas is 0 refers to the region of pure steam, while the area with high mole fractions which is outside the blue area is full of the released gas attached to the front of the steam chamber.

The steam chamber gradually expands with the injection of steam. The expansion of the steam chamber depends on the formation pressure at the conversion time. At the same time step of the SAGD process, a lower formation pressure at the conversion time shows a better expansion of the steam chamber. In the case of $2 \mathrm{MPa}$, after 5 years of the SAGD production, the upper part of the steam chamber expands 

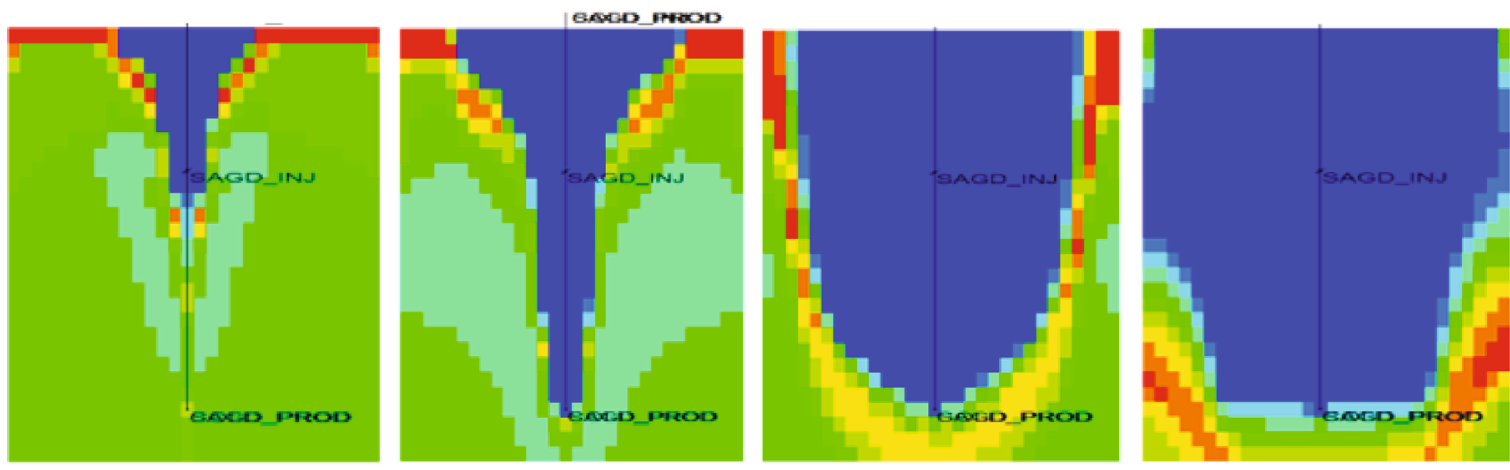

(a)
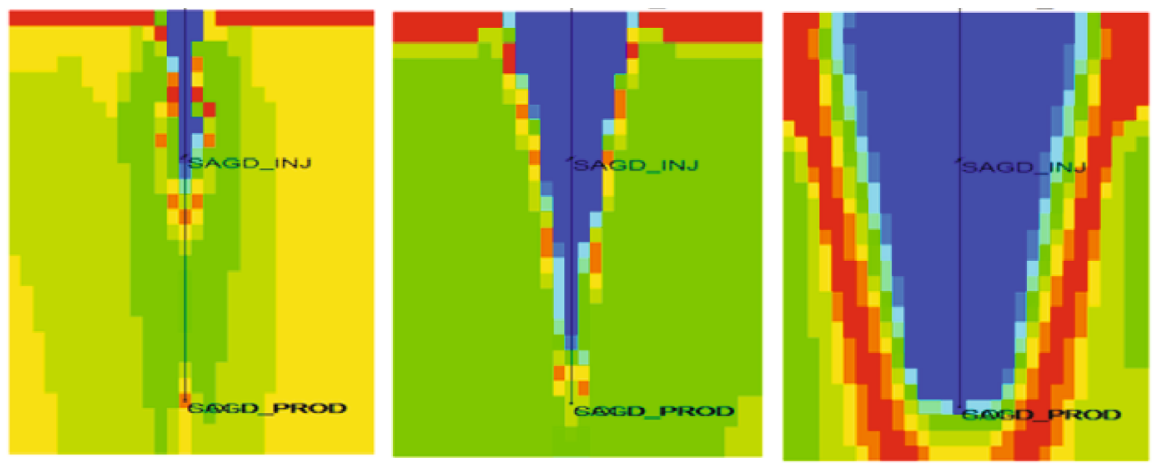

(b)

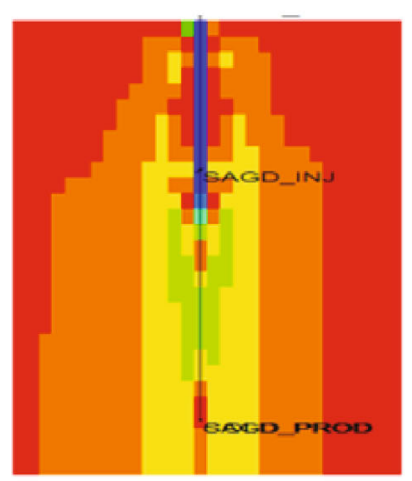

1 month

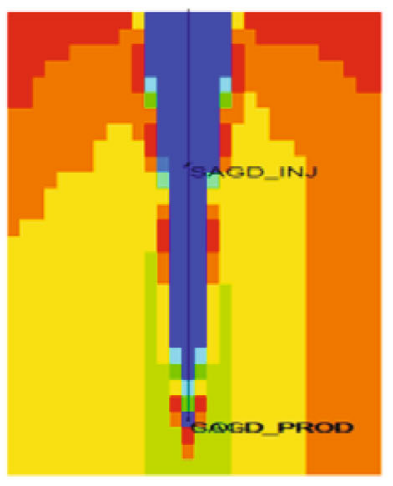

1 year
Mole fraction

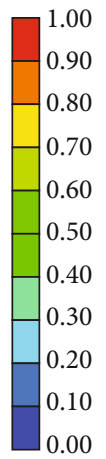

Mole fraction
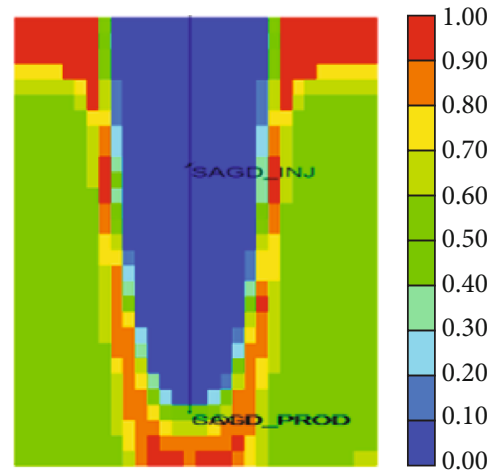

Mole fraction

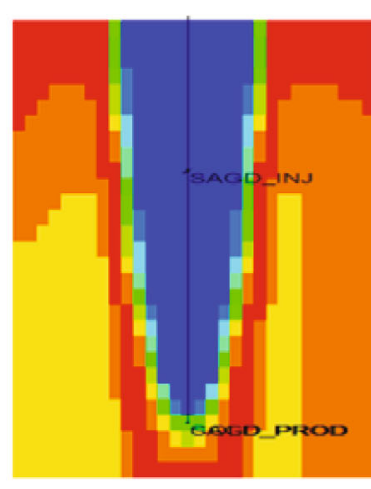

5 years

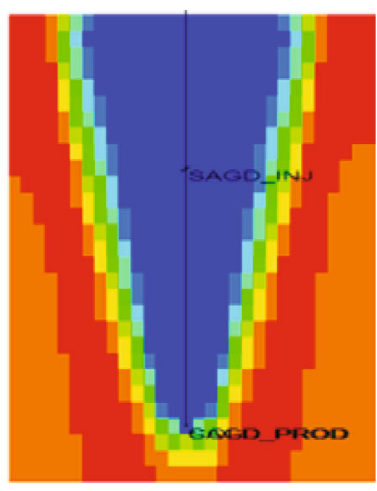

15 years

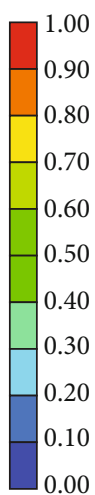

(c)

FIGURE 15: Mole fraction distribution of solution gas under the different formation pressure at conversion time: (a) $2 \mathrm{MPa}$; (b) $3 \mathrm{MPa}$; (c) $4 \mathrm{MPa}$.

to the edge of the model. In the case of $4 \mathrm{MPa}$, however, the area of the steam chamber is relatively small compared with the case of $2 \mathrm{MPa}$ at the same time step. It can be observed from Figure 15 that a layer of solution gas forms at the front of the steam chamber. When the CHOP process is switched to the SAGD process, more solution gas distributes at the edge of the steam chamber when the formation pressure is higher at the conversion time. Furthermore, the existence of solution gas hinders the heat transfer of steam chamber to the area with cold heavy oil, and therefore, the expansion of steam chamber is limited. As shown in Figure 15, when the CHOP process is switched to the SAGD process, a higher recovery can be achieved by the lower formation pressure at conversion time and the greater amount of steam injected into the reservoir. Although the cumulative oil-steam ratio is slightly lower, it is still within the acceptable range.

In summary, the duration of CHOP period of foamy extraheavy oil reservoir should be extended as long as possible, and the recovery process should be switched to the SAGD process at a relatively low formation pressure. In our case, the optimal conversion timing is the moment when the formation pressure drops to $2 \mathrm{MPa}$.

\section{Discussion}

Conversion timing of follow-up thermal recovery approaches of post-CHOP is a key factor to the entire recovery process in foamy extraheavy oil reservoirs. The optimal 
conversion timing can significantly increase the oil recovery in both the CHOP process and the follow-up thermal recovery stage. The findings of this study could help for better understanding of the CHOP and post-CHOP thermal techniques for foamy extraheavy oil reservoirs, and it can provide guidance for reservoir engineers to make better use of the thermal recovery techniques to further improve the recovery performance of foamy extraheavy oil reservoirs.

It is noteworthy that the research results of this study are more concerned about qualitative evaluation, which can provide a general scope of conversion timing for reservoir engineers. Although the exact values are given in typical heavy oil reservoirs, it may be necessary to restudy specific cases due to different pseudo-bubble point pressure.

In our future work, we will focus on the optimal operating parameters of thermal recovery techniques after the CHOP process.

\section{Summary and Conclusions}

(1) According to the experimental results, it can be concluded that the temperature has great influence on foamy oil flow stage during the CHOP process. The excessively high temperature has an adverse effect on the CHOP process of foamy extraheavy oil reservoir. Therefore, it is necessary to investigate the optimal conversion timing of the follow-up thermal recovery approaches after the $\mathrm{CHOP}$ process for the foamy extraheavy oil reservoir

(2) For the CSS method, excessively high pressure cannot give full play to the production potential of CHOP stage. When the pressure is too low, the heated crude oil cannot flow to the wellbore. Based on our simulation results, it is recommended to switch from the CHOP process to the CSS process at the conversion timing when the formation pressure drops to the pseudo-bubble point pressure. In our case, the optimal conversion timing is the moment when the formation pressure drops to $3.4 \mathrm{MPa}$

(3) For the SF method, high pressure cannot fully release the latent heat of steam and the amount of solution gas (which will hinder the heat transfer) in oil phase is higher under the high pressure. However, a low pressure leads to a relatively high viscosity of crude oil. As a result, there exists an equilibrium point which could balance the aforementioned effects. Our results show that the optimal conversion timing corresponds to the pseudo-bubble point pressure. In this work, the best conversion time for SF is the moment when the formation pressure drops to $3.4 \mathrm{MPa}$

(4) In the SAGD process, the adverse effects of released solution gas in foamy extraheavy oil reservoir outweigh the positive effects. As a result, the CHOP period of foamy extraheavy oil reservoir should be extended as long as possible, in order to fully utilize the advantage of foamy oil flow phase. In other words, the recovery process should be switched to the SAGD process at a relatively low formation pressure. In our case, the optimal conversion timing is the moment when the formation pressure drops to $2 \mathrm{MPa}$

\section{Nomenclature}

$X_{i}$ : $\quad$ Volumetric reaction rate between components

$F_{i}$ : $\quad$ Reaction factor

$\left[G_{\text {soleq }}\right]$ : Equilibrium concentration of solution gas

$\left[G_{\text {sol }}\right]$ : Concentration of solution gas

$\left[G_{\text {disp }}\right]$ : Concentration of dispersed bubbles.

\section{Data Availability}

The data used to support the findings of this study are included within the article.

\section{Conflicts of Interest}

The authors declare that they have no conflicts of interest.

\section{Acknowledgments}

This work was supported by the scientific research and technological development project of CNPC of 2021DJ3208.

\section{References}

[1] C. Wang, Y. Liu, Y. Du, Y. Gao, and Y. Sun, "Heavy-oil recovery by combined geothermal energy and cosolvent/water flooding," Energy, vol. 228, article 120681, 2021.

[2] X. Liang, L. Shi, L. Cheng, X. Wang, and Z. Ye, "Optimization of polymer mobility control for enhanced heavy oil recovery: based on response surface method," Journal of Petroleum Science and Engineering, vol. 228, article 120681, 2021.

[3] H. Jia, P. Huang, Y. Han et al., "Synergistic effects of Janus graphene oxide and surfactants on the heavy oil/water interfacial tension and their application to enhance heavy oil recovery," Journal of Molecular Liquids, vol. 314, article 113791, 2020.

[4] X. Sun, J. Cai, X. Li, W. Zheng, T. Wang, and Y. Zhang, "Experimental investigation of a novel method for heavy oil recovery using supercritical multithermal fluid flooding," Applied Thermal Engineering, vol. 185, article 116330, 2021.

[5] H. Saboorian-Jooybari, M. Dejam, and Z. Chen, "Heavy oil polymer flooding from laboratory core floods to pilot tests and field applications: half-century studies," Journal of Petroleum Science and Engineering, vol. 142, pp. 85-100, 2016.

[6] S. Huang, Y. Zhu, J. Ding, X. Li, and Y. Xue, "A semi-analytical model for predicting inflow profile of long horizontal wells in super-heavy foamy oil reservoir," Journal of Petroleum Science and Engineering, vol. 195, article 107952, 2020.

[7] X. Zhou, Q. Yuan, X. Peng, F. Zeng, and L. Zhang, “A critical review of the $\mathrm{CO}_{2}$ huff 'n' puff process for enhanced heavy oil recovery," Fuel, vol. 215, pp. 813-824, 2018.

[8] X. Dong, H. Liu, Z. Chen, K. Wu, N. Lu, and Q. Zhang, "Enhanced oil recovery techniques for heavy oil and oilsands reservoirs after steam injection," Applied Energy, vol. 239, pp. 1190-1211, 2019. 
[9] X. Sun, Z. Song, L. Cai, Y. Zhang, and P. Li, "Phase behavior of heavy oil-solvent mixture systems under reservoir conditions," Petroleum Science, vol. 17, no. 6, pp. 1683-1698, 2020.

[10] S. Pei, G. Cui, Y. Wang et al., "Air assisted in situ upgrading via underground heating for ultra heavy oil: experimental and numerical simulation study," Fuel, vol. 279, article 118452, 2020.

[11] M. Ahmadi and Z. Chen, "Challenges and future of chemical assisted heavy oil recovery processes," Advances in Colloid and Interface Science, vol. 275, article 102081, 2020.

[12] O. Alade, M. Hamdy, M. Mahmoud et al., "A preliminary assessment of thermochemical fluid for heavy oil recovery," Journal of Petroleum Science and Engineering, vol. 186, article 106702, 2020.

[13] X. Li, Y. Yin, Z. Yang, Y. Shen, and Z. Liu, "Produced gas reinjection based cyclic solvent processes for foamy oil reservoirs in the Eastern Orinoco Belt, Venezuela," in SPE Canada Heavy Oil Technical Conference, pp. 1-11, Calgary, Canada, 2016.

[14] Y. Bao, L. He, X. Lv et al., "An evaluation of enhanced oil recovery strategies for extra heavy oil reservoir after cold production without sand in Orinoco, Venezuela," in SPE Trinidad and Tobago Section Energy Resources Conference, pp. 1-18, Port of Spain, Trinidad and Tobago, 2018.

[15] M. Wu, X. Lu, J. Yang, Z. Liu, and F. Zeng, "Experimental analysis of optimal viscosity for optimizing foamy oil behavior in the porous media," Fuel, vol. 262, article 116602, 2019.

[16] J. Sheng, B. Maini, R. E. Hayes, and S. Tortike, "Critical review of foamy oil flow," Transport in Porous Media, vol. 35, no. 2, pp. 157-187, 1999.

[17] A. Firoozabadi and A. Aronson, "Visualization and measurement of gas evolution and flow of heavy and light oil in porous media," SPE Reservoir Evaluation and Engineering, vol. 2, no. 6, pp. 550-557, 1999.

[18] A. Yrigoyen and G. Carvajal, "Performance of a foamy oil reservoir in pseudo-undersaturated state with associated aquifer," in SPE Latin American and Caribbean Petroleum Engineering Conference, pp. 1-8, Buenos Aires, Argentina, 2001.

[19] R. Kumar and J. Mahadevan, "Well-performance relationships in heavy-foamy-oil reservoirs," SPE Production \& Operations, vol. 27, no. 1, pp. 94-105, 2012.

[20] B. S. Busahmin and B. B. Maini, "Effect of solution-gas-oilratio on performance of solution gas drive in foamy heavy oil systems," in Canadian Unconventional Resources and International Petroleum Conference, pp. 1-10, Calgary, Canada, 2010.

[21] H. Zhao, Y. Chang, and X. Guo, "Foamy oil properties and reservoir performance," Petroleum Science and Technology, vol. 34, no. 16, pp. 1512-1519, 2016.

[22] H. Pinto, X. Wang, and I. Gates, "On the ratio of energy produced to energy injected in SAGD: long-term consequences of early stage operational decisions," Journal of Petroleum Science and Engineering, vol. 199, article 108271, 2021.

[23] J. Jimenez, "The field performance of SAGD projects in Canada," in International Petroleum Technology Conference, pp. 1-11, Kuala Lumpur, Malaysia, 2008.

[24] F. Kirmani, A. Raza, R. Gholami, M. Z. Haidar, and C. Fareed, "Analyzing the effect of steam quality and injection temperature on the performance of steam flooding," Energy Geoscience, vol. 2, no. 1, pp. 83-86, 2021.

[25] Y. Zhao, "Laboratory experiment and field application of high pressure and high quality steam flooding," Journal of Petroleum Science and Engineering, vol. 189, article 107016, 2020.
[26] Q. Zhang, H. Liu, X. Kang et al., "An investigation of production performance by cyclic steam stimulation using horizontal well in heavy oil reservoirs," Energy, vol. 218, article 119500, 2021.

[27] E. Luo, Z. Fan, Y. Hu et al., "An efficient optimization framework of cyclic steam stimulation with experimental design in extra heavy oil reservoirs," Energy, vol. 192, article 116601, 2020.

[28] R. Coll, G. Pena, J. Guitian, A. Mancera, and E. Escobar, "Surface facilities for a giant thermal EOR project-cost and HSE implications of alternative fuels for steam generation," in Abu Dhabi International Petroleum Exhibition \& Conference, pp. 1-7, Abu Dhabi, UAE, 2017.

[29] E. Escobar, R. Coll, M. F. L. Carrera, and S. Pérez, "Overcoming the challenge of forecasting EOR in giant extra-heavy oil fields," in Abu Dhabi International Petroleum Exhibition \& Conference, pp. 1-15, Abu Dhabi, UAE, 2017.

[30] CMG User's Manual, Version 2015, Computer Modelling Group Ltd., Calgary, AB, Canada, 2015.

[31] W. Huang and M. Hight, "Evaluation of steamflood processes with horizontal wells," SPE Reservoir Engineering, vol. 4, no. 1, pp. 69-76, 1989.

[32] Z. Cheng and Y. Zhou, "Optimization on technologic policy limitation of steam flooding in horizontal wells," Journal of Oil and Gas Technology, vol. 35, pp. 139-142, 2013. 